\title{
A Centrifuge Model Test of the Ground Motion Response in a Moderately Stiff Soil
}

\author{
Jing-Yan Lan $\mathbb{D}^{1},{ }^{1}$ Ting Wang, ${ }^{1}$ Diwakar Khatri Chhetri, ${ }^{2}$ Mohammad Wasif Naqvi, \\ and Liang-Bo $\mathrm{Hu} \mathbb{i D}^{2}$ \\ ${ }^{1}$ Guangxi Key Laboratory of Geomechanics and Geotechnical Engineering, Guilin University of Technology, Guilin, \\ Guangxi 541004, China \\ ${ }^{2}$ Department of Civil and Environmental Engineering, University of Toledo, Toledo, $\mathrm{OH} 43606$, USA
}

Correspondence should be addressed to Liang-Bo Hu; liangbo.hu@utoledo.edu

Received 18 September 2020; Accepted 16 January 2021; Published 30 January 2021

Academic Editor: Zhixiong Li

Copyright (C) 2021 Jing-Yan Lan et al. This is an open access article distributed under the Creative Commons Attribution License, which permits unrestricted use, distribution, and reproduction in any medium, provided the original work is properly cited.

The ground motion response in a moderately stiff soil in seismic events has been traditionally studied based on the actual field records which, however, have yet to offer consistent results regarding the amplification effect of the ground motion. In the present study, a centrifuge model of the moderately stiff soil field is designed to study the amplification effect of the ground motion in response to seismic loads. Four El Centro waves of different strengths are used as the input wave at the base under a gravitational field of $75 \mathrm{~g}$. Ground motion data at different depths are collected via a number of sensors to study the acceleration peak, time history, and response spectrum of the ground motion. The measured amplitude and energy of seismic waves are found to gradually increase from the bottom to the surface during the propagation of seismic waves, and the peak acceleration at the surface is significantly magnified. The response spectrum analysis shows that the acceleration response spectrum gradually moves to the high-frequency direction from the base to the surface and the value of the response spectrum decreases with the increase of the depth in the present study.

\section{Introduction}

Seismic field evidence has shown that the site conditions are important factors that influence the ground motion response and the seismic damage [1]. In the past few decades, advances in the field of seismic engineering and continuous development of ground motion monitoring technologies have offered various methods for characterizing the ground motion site effect, including the empirical method [2-5], the numerical simulation method [6-12], and the indirect estimation method [13]. Some of these methods have been incorporated into the seismic design codes in various countries and are widely used by the engineering communities [14-16]. Of particular interest is the ground response of the natural soil site condition commonly encountered; a typical soil usually possesses a modest stiffness, i.e., the site condition is neither extremely stiff nor extremely soft, and typically can be described as moderately stiff. For instance, in
China, a very large part of the country can be considered to be located in moderately stiff soil sites [17]. The site conditions are typically categorized based on the soil site's shear wave velocity in several national standards and building codes. In 1997 Uniform Building Code [14] and NEHRP [15], a site with a moderate range of shear wave velocity between $180 \mathrm{~m} / \mathrm{s}$ and $360 \mathrm{~m} / \mathrm{s}$ is considered as a stiff soil profile, which is lower than the hard rock, rock, and soft rock but higher than the soft soil profile, whereas a soil of such range is considered as a moderately stiff soil site in Chinese Earthquake Design Code [16].

The strong amplification effect of ground motion in a moderately stiff soil site has been recognized to be a factor of concern for seismic evaluation, even though it is believed that a moderately stiff site is in general a favorable location for earthquake resistance. Seismic damage of rigid structures with a short natural vibration period is usually severe on very stiff sites [18]; therefore, it is strongly possible that the 
response of moderately stiff site conditions cannot be underestimated either. However, several studies based on the actual field observation records have reported significantly different results about the amplification effect of ground motion in the moderately stiff site conditions [19], possibly due to the particularity of geological conditions and the uncertainty of seismic events.

The principal response of the ground motion is represented by the amplification effect across the depth from the ground motion source to the ground surface. However, most of the recent research studies have mainly focused on the amplification effect of ground motion at the ground surface or the influence of different geological terrains [20-22]; the amplification effect below the ground surface has not yet been extensively investigated. Lai et al. [23] used a layered shear box and conducted a series of centrifuge tests on Nevada dense sand to simulate the response process of the soil under a one-dimensional seismic response. Lee et al. [24] carried out centrifugal model tests on saturated sand and dry sand and studied the relationship of amplification factor with base acceleration and soil depth. Liu et al. [25] studied the seismic response of sandy soil foundation with a centrifuge shaking table test and analyzed the boundary effect of the laminated model box. It was then extended to different test conditions of sandy soil, clay, and layered soil under the input of natural waves. The results showed that the low-frequency amplification at the sand surface is most significant and the peak acceleration amplification factor is around 1.4. Afacan [26] simulated the ground motion response of soft clays with centrifugal model tests and reported that the amplification factor of surface acceleration decreased with the increase in base acceleration. Hashash et al. [27] studied the medium-dense sand in centrifuge earthquake motion and compared the centrifugal testing results with those from different modeling methods before eventually suggesting some strategies to predict one-dimensional site response. Besides the abovementioned laboratory efforts which are primarily devoted to sands or soft clays, limited seismic field observation records available do not offer consistent conclusions regarding the amplification effect in moderately stiff sites, either [28, 29]. Much research is still needed to improve the understanding of the amplification effect, in particular, in moderately stiff soil sites.

The present study is aimed to simulate the ground response of a moderately stiff soil site with dynamic centrifuge model testing to identify the variation of the amplification effect with depth. Under the action of different intensity of ground motion input sources, the present study attempts to obtain the complete time history records of ground acceleration at different depths of ground soil, analyze the critical ground motion parameters, and eventually reveal the nonlinear amplification effect of ground motion at different depths of a moderately stiff soil.

\section{Test Procedure}

The soil for the test was collected from a construction site in Binhai District, Tianjin, China; it was retrieved from $10 \mathrm{~m}$ below the ground surface, totaling approximately $1 \mathrm{~m}^{3}$. This dense clay can be classified as a lean clay whose properties and testing conditions are summarized in Table 1. After a typical process of drying including air drying, drying-grinding, screening, and stirring, the test soil with a density of $2.0 \mathrm{~g} / \mathrm{cm}^{3}$, moisture content of $15 \%$, and void ratio of 0.48 was prepared. The adopted moisture content and density are selected based on empirical data on typical moderately stiff soils found in China. The soil was prepared and compacted at the selected moisture content in four layers in the model box.

2.1. Test Design. Figure 1 shows the centrifuge testing system used in the present study. The TLJ-500 centrifuge testing system of Chengdu University of Technology (China) is employed to provide high-precision one-way horizontal vibration under the $75 \mathrm{~g}$ centrifugal acceleration. The model box used in the test is a laminated ring-type layered shear model box. Some studies [25] have shown that the laminated ring-type layered shear model box can effectively reduce the lateral boundary effect. The size of the model box is $1000 \mathrm{~mm}$ (length) $\times 600 \mathrm{~mm}$ (width) $\times 740 \mathrm{~mm}$ (height), and the actual mass is about $380 \mathrm{~kg}$. It is the largest shear model box in China at present. The shear box consists of 12 layers of hollow aluminum rings. The maximum relative displacement of the two adjacent rings can reach $6 \mathrm{~mm}$. A $1 \mathrm{~mm}$ thick strong rubber mold is installed in the box to ensure the tightness of the model box, which makes it also suitable for soil sample tests under high moisture content.

In the present study, the centrifuge model is carefully planned for the testing of a homogeneous hard clay site. In order to reduce the influence of the lateral boundaries and obtain more accurate acceleration records, five microacceleration sensors are placed in the middle of the model box from top to bottom to monitor the strong vibration. The widely used El Centro seismic wave is selected as the input wave at the base to simulate earthquake motion, and the seismic wave with different intensity is simulated by adjusting the input peak acceleration. The acceleration peak value, time history, and response spectrum of the tested soil are obtained based on the measurements from the acceleration sensors.

The dimensions of the test model and the locations of the sensors are shown in Figure 2. It is generally beneficial to avoid excessively large or tall boxes that may result in significant inaccuracies; hence, to simulate the soil of a modest depth, for example, $30 \mathrm{~m}$ in the moderately stiff site, the height of the soil is designed to be $400 \mathrm{~mm}$, with a centrifugal acceleration of $75 \mathrm{~g}$ used in the present study. Consequently, the main similarity constants (model/field) involved are as follows: acceleration similarity factor $C_{a}=75$, time similarity factor $C_{t}=1 / 75$, and frequency similarity factor $C_{f}=75$.

The dynamic parameters of the soil site include the maximum dynamic shear modulus $G_{\max }$ and shear wave velocity $V_{s}$ of the soil layer. The empirical formula for cohesive soil given by Hardin and Black [30] is widely used and can be expressed as follows:

$$
G_{\max }=102 \frac{(2.973-e)^{2}}{1+e}\left(\sigma_{0}\right)^{0.5},
$$

where $\sigma_{0}$ is the effective consolidation stress and $e$ is the void ratio. Meanwhile, the shear wave velocity $V_{s}$ can be obtained 
TABLE 1: Basic properties of the tested soil.

\begin{tabular}{lc}
\hline Density $\left(\mathrm{g} / \mathrm{cm}^{3}\right)$ & 2.0 \\
\hline Moisture content & $15 \%$ \\
Void ratio & 0.48 \\
Plastic limit & $12 \%$ \\
Liquid limit & $44 \%$ \\
Specific gravity & 2.6 \\
Cohesion $(\mathrm{kPa})$ & 23.0 \\
Fiction angle $\left({ }^{\circ}\right)$ & 25.6 \\
\hline
\end{tabular}

from the well-known wave velocity equation, $G_{\max }=\rho V_{s}^{2}$, once $G_{\max }$ is determined. Figure 3 shows the shear wave velocity calculated from these equations. It can be concluded that the shear wave velocity of the site at the depth of $30 \mathrm{~m}$ is approximately $205 \mathrm{~m} / \mathrm{s}$. According to the NEHRP site classification code [15], the model site can be classified as a Class D (stiff soil) site.

2.2. Input Waves for Ground Motion. In the present centrifuge shaking table test, an El Centro wave is used to simulate the ground motion source; the intensity of each input seismic wave is controlled by controlling its peak acceleration, which is summarized in Table 2 . It is worth noting that in order to avoid or reduce the cumulative effect of continuous input of the four seismic waves, the vibration tests of four seismic waves were not carried out continuously. After the completion of a vibration test, the sidewalls of the model box were fixed so as to restrain its potential movement and the centrifuge was run continuously for five hours in an attempt to restore the model to the initial state, before the next vibration test was conducted.

It is noted that when applying the seismic wave in each vibration test, both the amplitude and the duration of the original input seismic wave should be firstly scaled according to the similarity factor $\left(C_{a}=C_{f}=75\right)$ before the base ground motion input for the actual centrifuge model test can be obtained. The final actual loaded seismic waveform is shown in Figure 4, including the four seismic waves summarized in Table 2.

\section{Results}

3.1. Peak Value of Ground Motion and Its Variation with Depth. Figure 5 shows the acceleration-time history recorded by the five sensors in the model box in response to the four input waves; the locations of the five sensors A1 A5 in the model box correspond to the depth of $30.0 \mathrm{~m}, 22.5 \mathrm{~m}$, $15.0 \mathrm{~m}, 7.5 \mathrm{~m}$, and 0.0 in the field, respectively. It is evident from each response in Figure 5 that the ground motion across the depth is of high consistency in the waveform and basically retains the waveform of the input seismic wave as shown in Figure 4. Because of the small filtering effect, the amplitude and energy of the seismic wave increase gradually in the wave propagation process from the bottom.

The peak ground acceleration (PGA) value at each sensor is also indicated in Figure 5. These values are plotted across the depth in Figure 6. Overall, it shows a considerable amplification effect in the moderately stiff soil field, especially when the amplitude of the input seismic wave is high. However, the variation is not linear and the peak value appears to approach the maximum near the ground surface.

It is useful to normalize the peak acceleration of the ground motion with respect to the input acceleration to highlight the amplification effect. A peak acceleration amplification factor, $F_{a}$, is introduced, as it is defined as the ratio of the peak acceleration recorded in each layer to the peak input from the base. Figure 7 shows the distribution of the amplification factor under all four different input waves in the present study. It can be seen that the amplification factor in the present study varies from the bottom to the surface. The three responses to EL-2, EL-3, and EL-4 seem to yield very consistent results, whereas the EL-1 wave at a low input acceleration leads to larger variations across the depth. The results of the amplification factor $F_{a}$ at the ground surface are summarized in Table 3. They are between 1.95 and 2.19 with an average value of 2.01 . Overall, the amplification factor at the ground surface grows with the increase of the input peak, with the exception of EL-3 which leads to a slightly smaller amplification factor.

It is of interest to assess the presented results with several available recent findings [25, 27, 31]. In Figure 7, the results of each study examined are denoted by the authors followed by the year published. It should be noted that the differences among these studies could result from different tested soils and different base input peak accelerations. Lee et al. [24] used a base input peak acceleration of $0.2 \mathrm{~g}$ on a saturated sand. Cao et al. [31] applied to a soft clay a base input peak acceleration of $0.10 \mathrm{~g}$, $0.15 \mathrm{~g}$, and $0.40 \mathrm{~g}$. Hashash et al. [27] investigated a mediumdense sand with a peak base acceleration of $0.33 \mathrm{~g}$ and $0.76 \mathrm{~g}$. Across all results summarized herein, there is roughly a common trend that the amplification factor first decreases from the bottom before increasing upward. The responses in the soft clay as studied by Cao et al. [31] actually demonstrate the attenuation effect, as the amplification factors are below 1 . Results on sands from Lee et al. [24] and Hashash et al. [27] indicate some modest amplification effect. The present centrifuge study on a moderately stiff clay demonstrates a significantly greater amplification effect, as the maximum amplification factor in each test is between 1.95 and 2.19.

\subsection{Acceleration Response Spectrum and Its Amplification} Effect. The response spectrum characteristic is also an important index to characterize and describe the ground motion and it is usually affected by the geological conditions. It is well known that the response spectrum analysis plays an important role in the seismic design of structures [32]. Based on the acceleration-time history results presented in Figure 5 , the acceleration response spectra of different layers can be calculated under different wave inputs and the results are plotted in Figure 8. The acceleration response spectrum from the bottom to the surface tends to move to the highfrequency direction, and the value of the response spectrum decreases with the increase of the depth. These trends are very consistent in all four tests. It can also be seen that the response spectrum from EL-1 to EL-4 generally increases as the peak acceleration of the base input increases. 


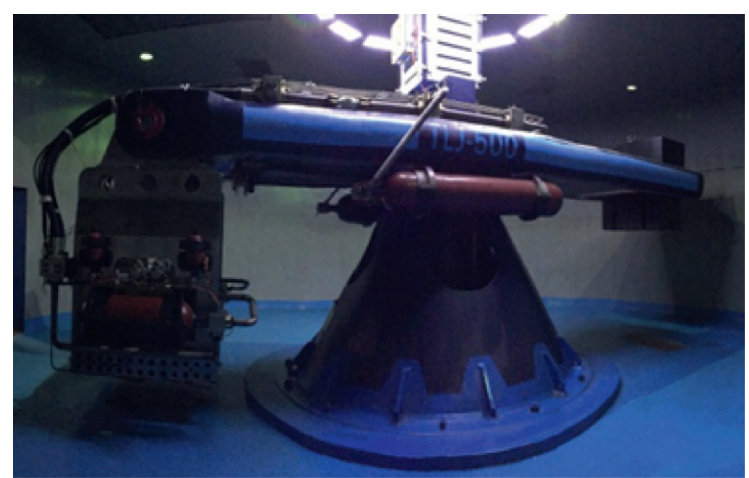

(a)

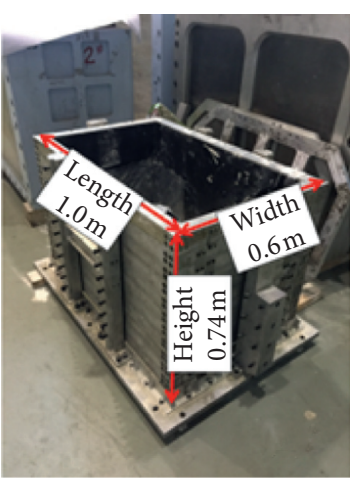

(b)

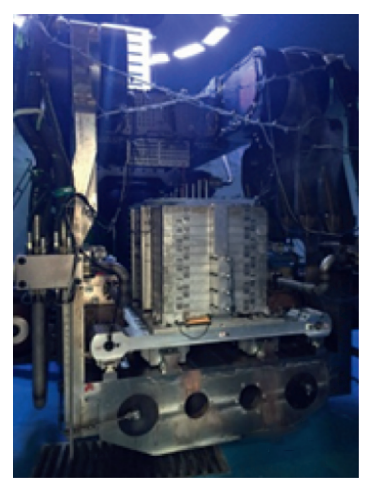

(c)

Figure 1: (a) The TLJ-500 centrifuge testing system; (b) laminar model box; (c) shaking table.

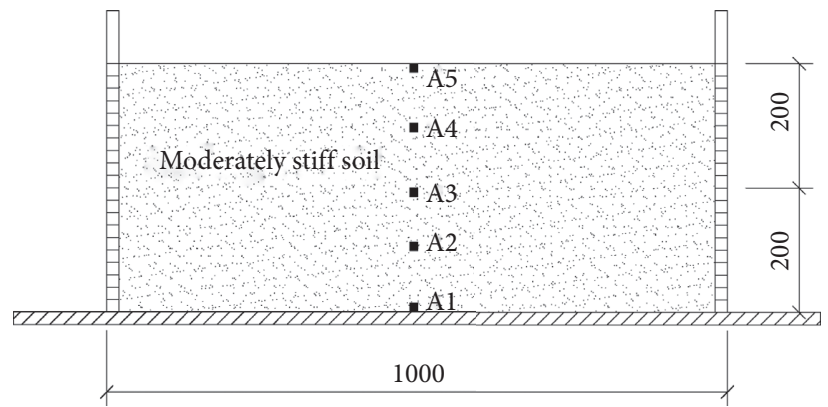

FIgURE 2: Locations of sensors in the test model (all dimensions in $\mathrm{mm}$ ).

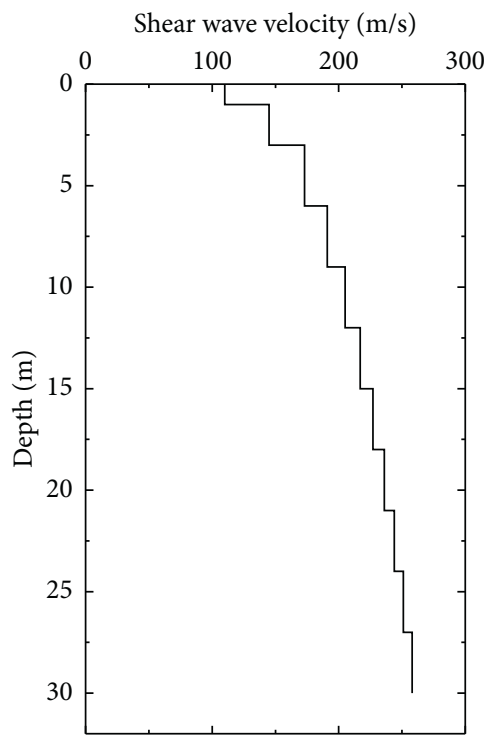

FIGURE 3: Shear wave velocity across the depth.

Table 2: Ground motion input in the centrifuge model test.

\begin{tabular}{lcc}
\hline Wave & Peak value $(\mathrm{g})$ & Duration $(\mathrm{s})$ \\
\hline EL-1 & 0.032 & 60 \\
EL-2 & 0.124 & 60 \\
EL-3 & 0.140 & 60 \\
EL-4 & 0.169 & 60 \\
\hline
\end{tabular}

To explore the amplification effect on the acceleration response spectrum, a normalized acceleration response spectrum ratio, defined as the ratio of the acceleration response spectrum to the input ground motion response spectrum at each period, is calculated and plotted in Figure 9. It can be seen the variations of this ratio mainly fall between 0.7 and 10 . The average ratio is close to $1.8 \sim 1.9$ as 


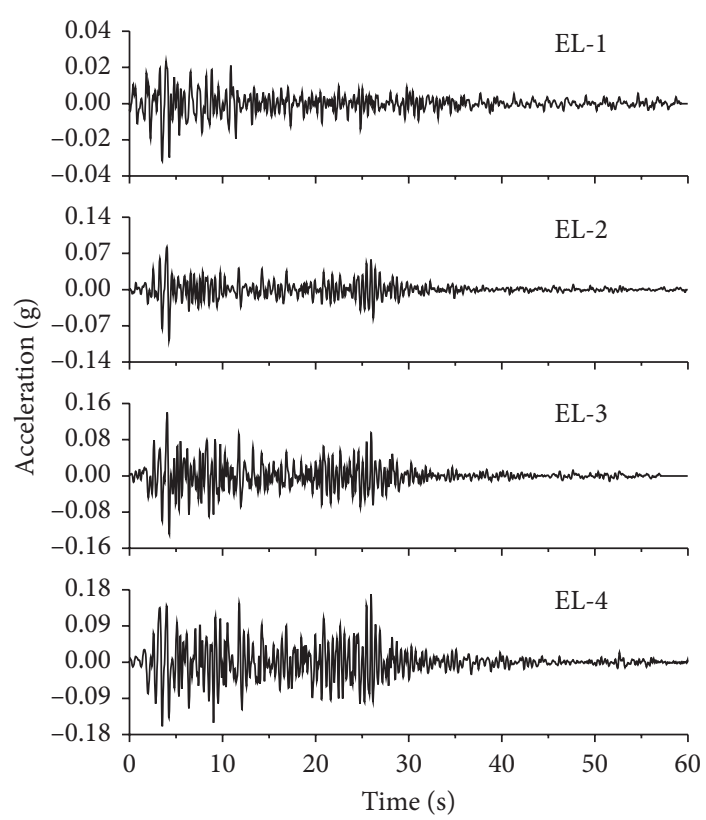

Figure 4: Actual input of seismic wave for the 4 vibration tests.

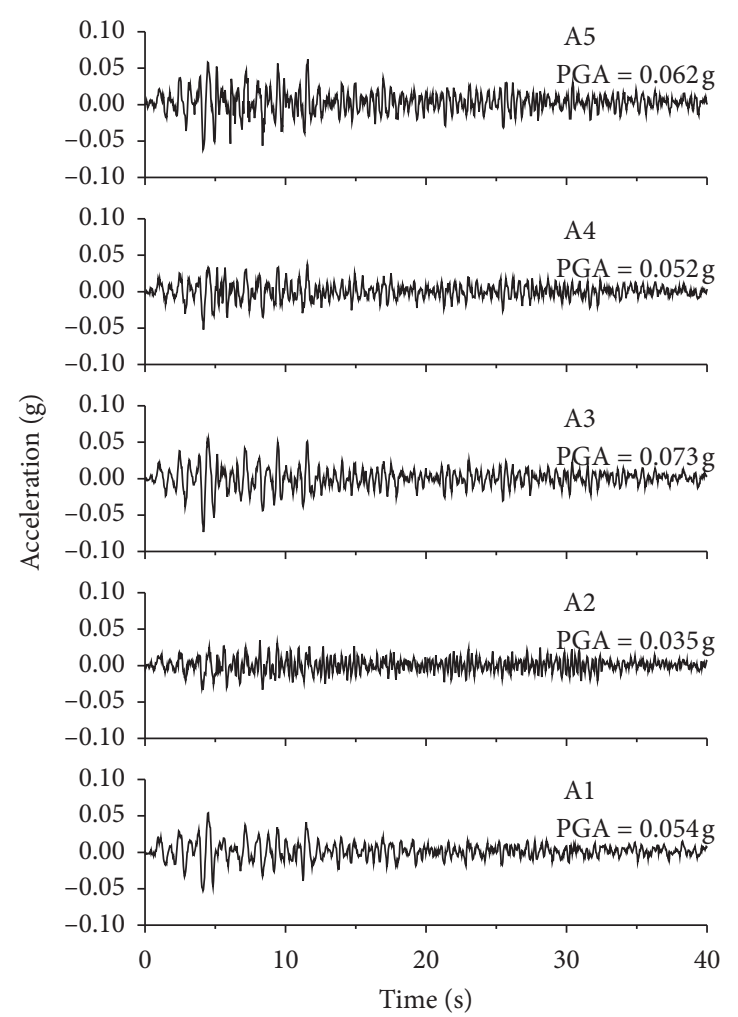

(a)
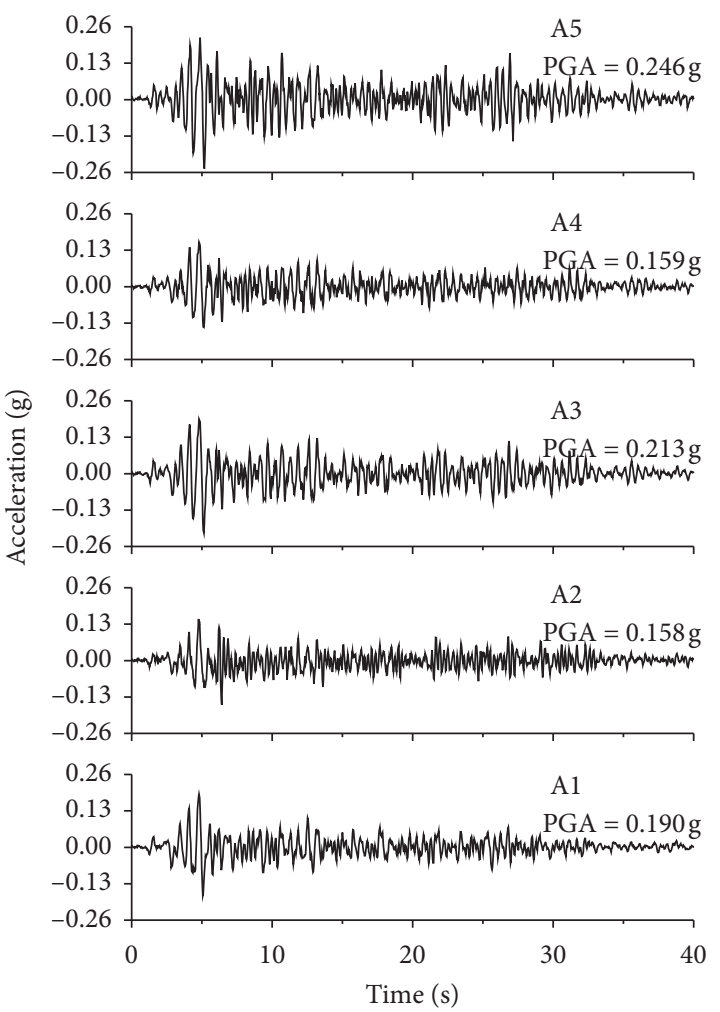

(b)

Figure 5: Continued. 


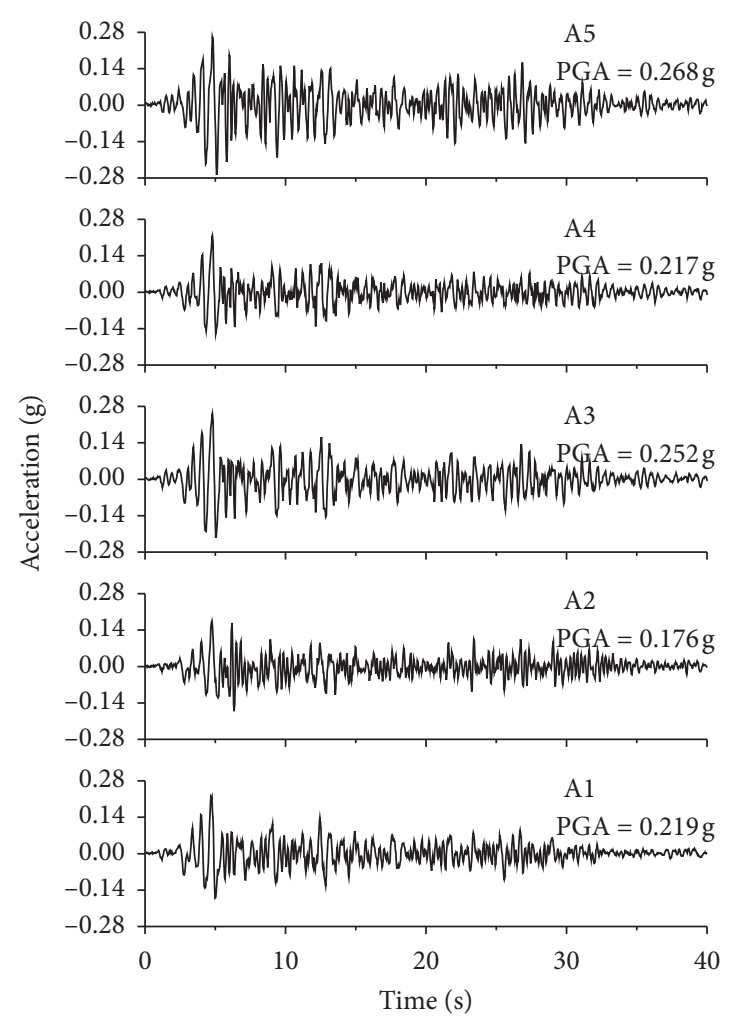

(c)

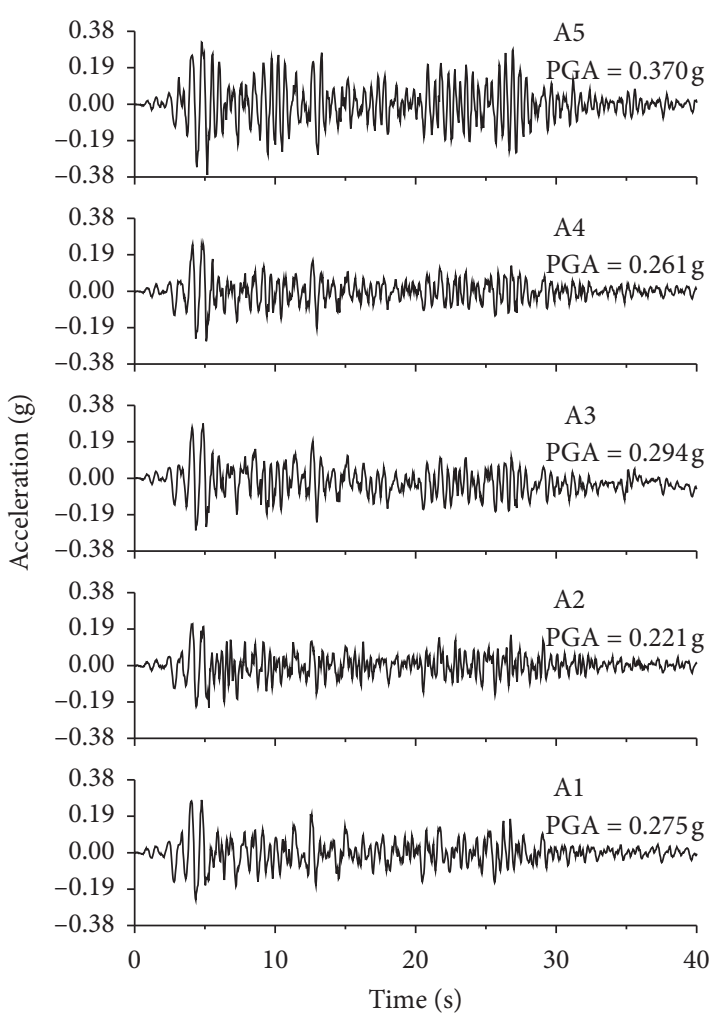

(d)

Figure 5: Acceleration-time history response. (a) EL-1; (b) EL-2; (c) EL-3; (d) EL-4.

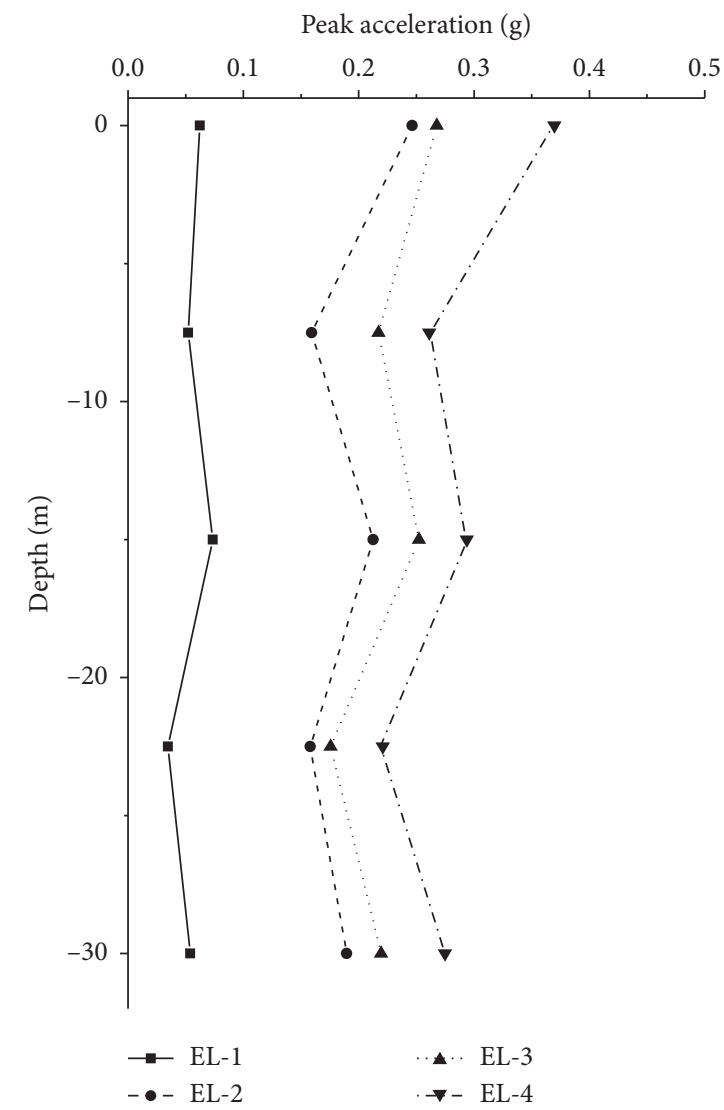

Figure 6: Variation of the peak acceleration with depth under four input waves. 


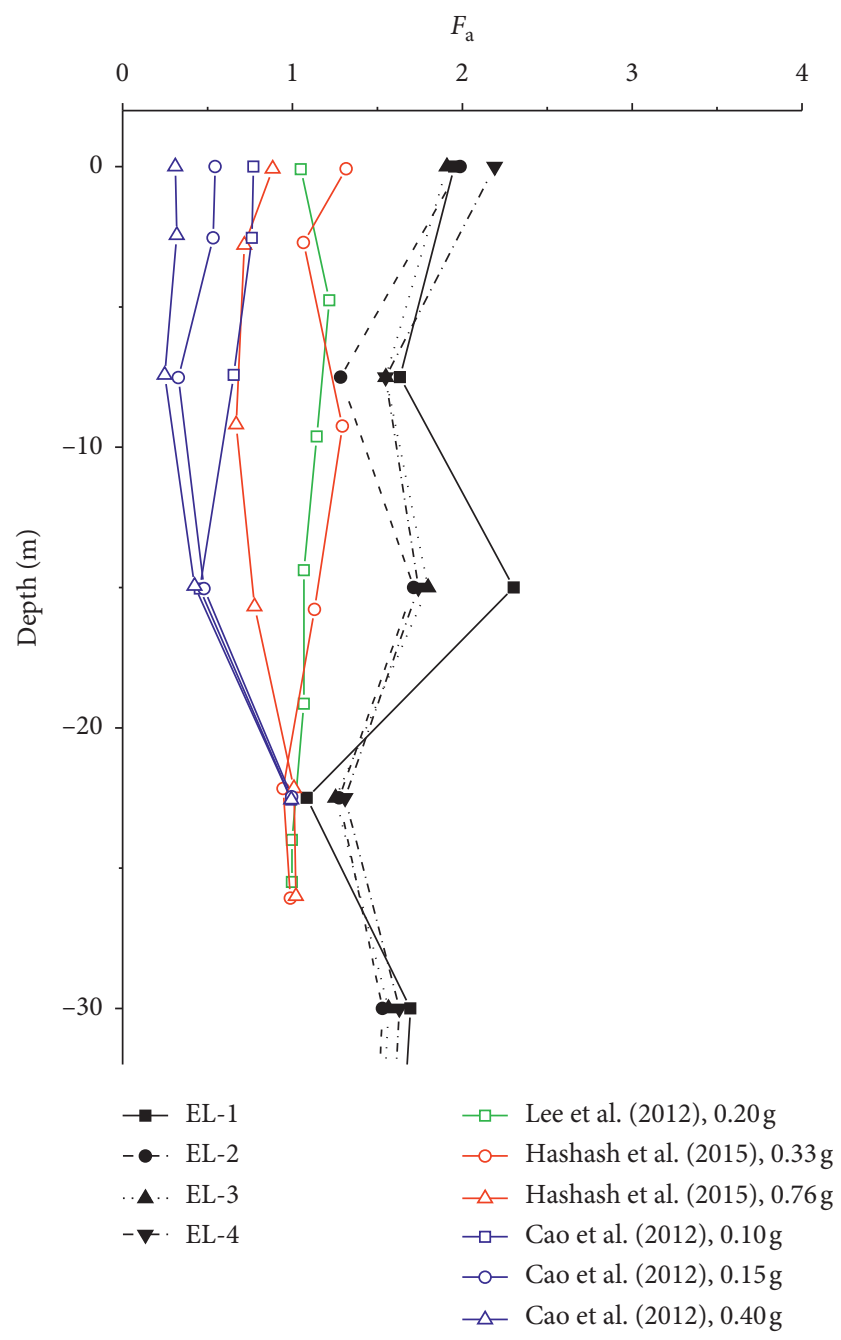

FIGURE 7: Variation of the peak acceleration amplification factor, examined along with some existing research results.

TABLE 3: Ground motion amplification factor $\left(F_{a}\right)$ under various test conditions.

\begin{tabular}{lcr}
\hline Wave input & Input peak $(\mathrm{g})$ & Ground surface $F_{a}$ \\
\hline EL-1 & 0.032 & 1.95 \\
EL-2 & 0.124 & 1.99 \\
EL-3 & 0.140 & 1.91 \\
EL-4 & 0.169 & 2.19 \\
\hline
\end{tabular}



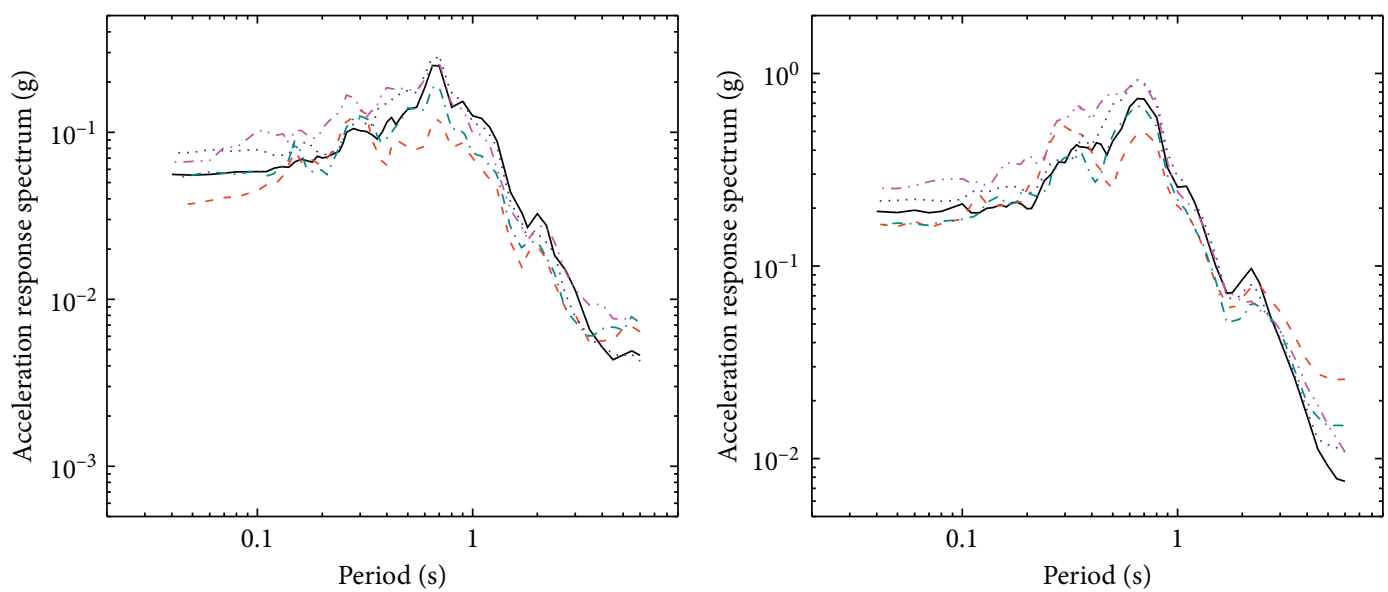

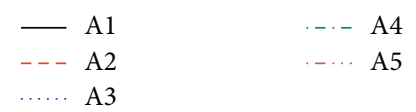

(a)

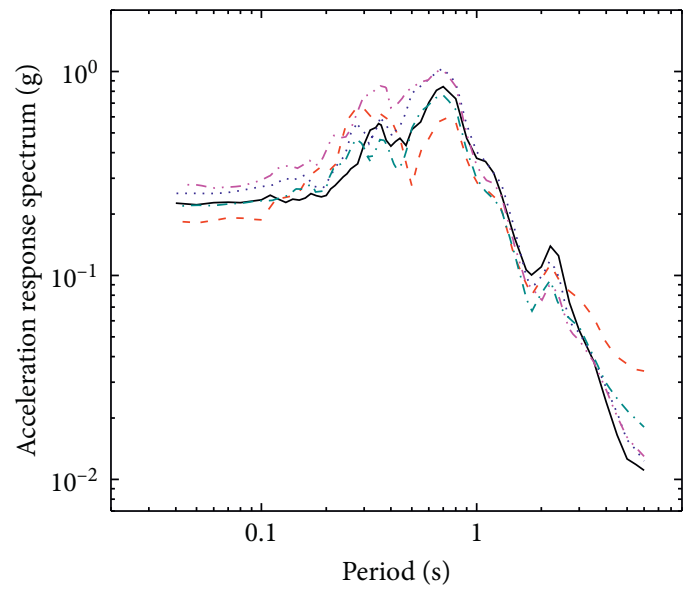

$-\mathrm{A} 1$
$---\mathrm{A} 2$ A3

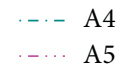

(c)

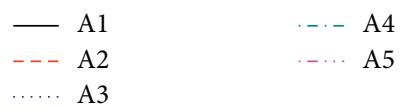

(b)

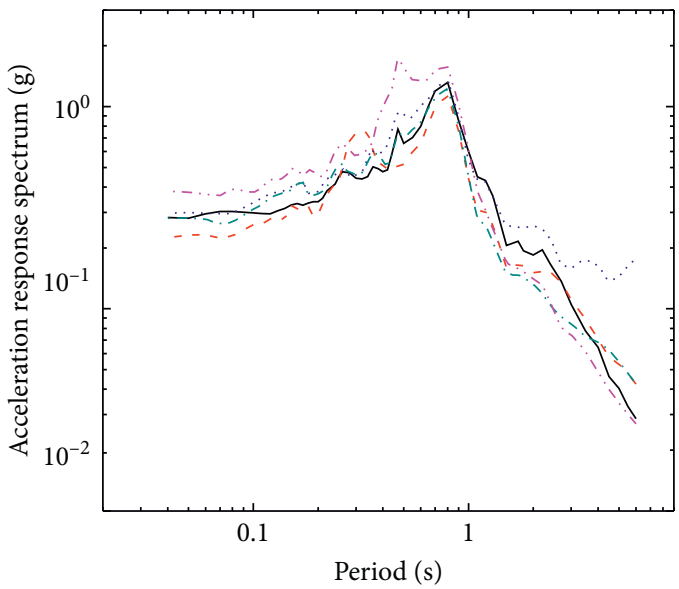

$\begin{array}{ll}- & \mathrm{A} 1 \\ --- & \mathrm{A} 2 \\ \cdots . . & \mathrm{A} 3\end{array}$

$\ldots$ A4

. - ... A5

(d)

Figure 8: Acceleration response spectrum. (a) EL-1; (b) EL-2; (c) EL-3; (d) EL-4. 


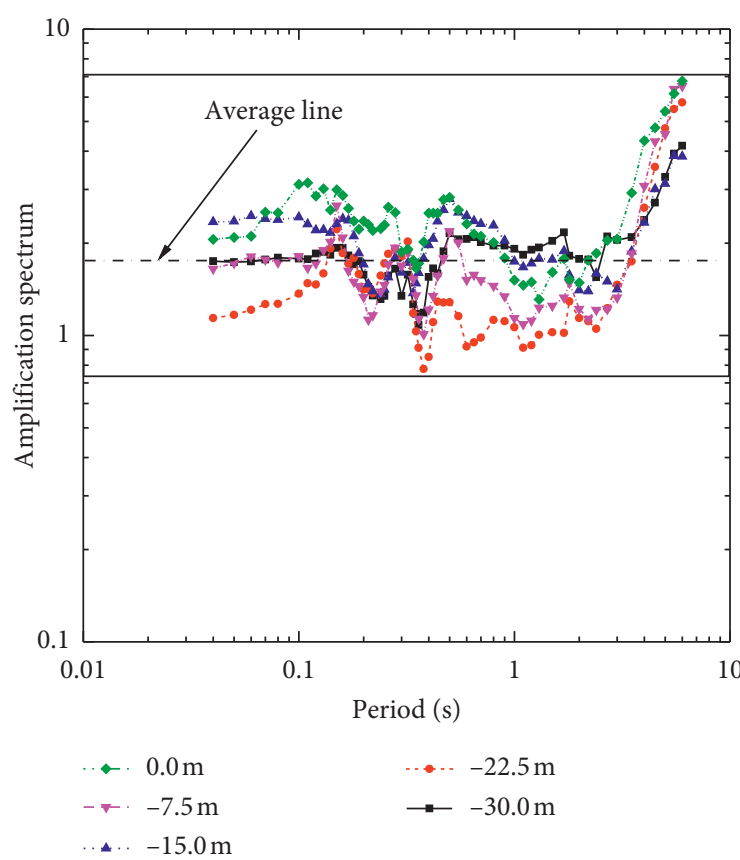

(a)

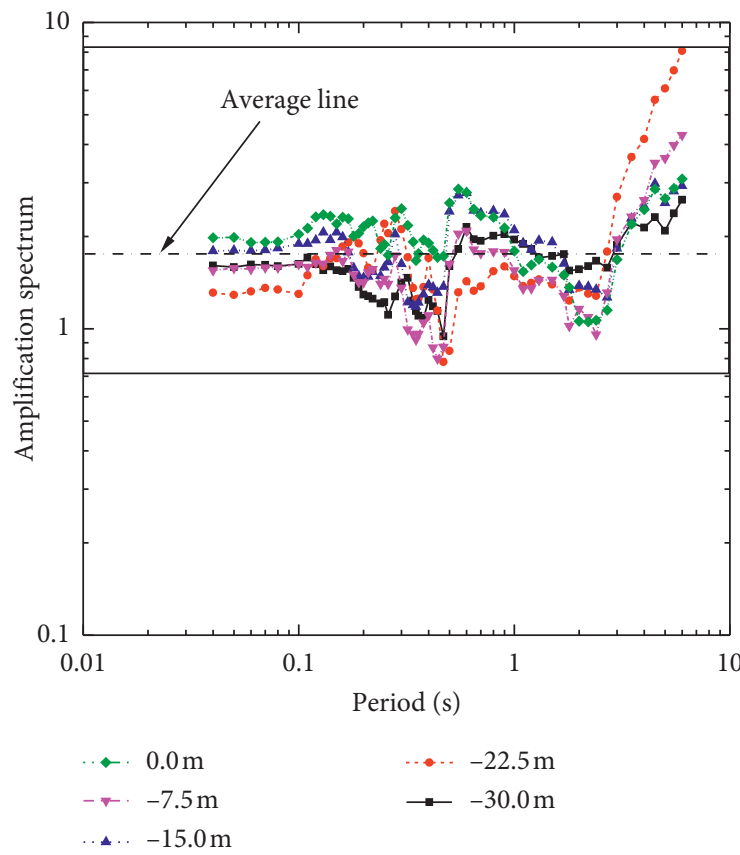

(c)

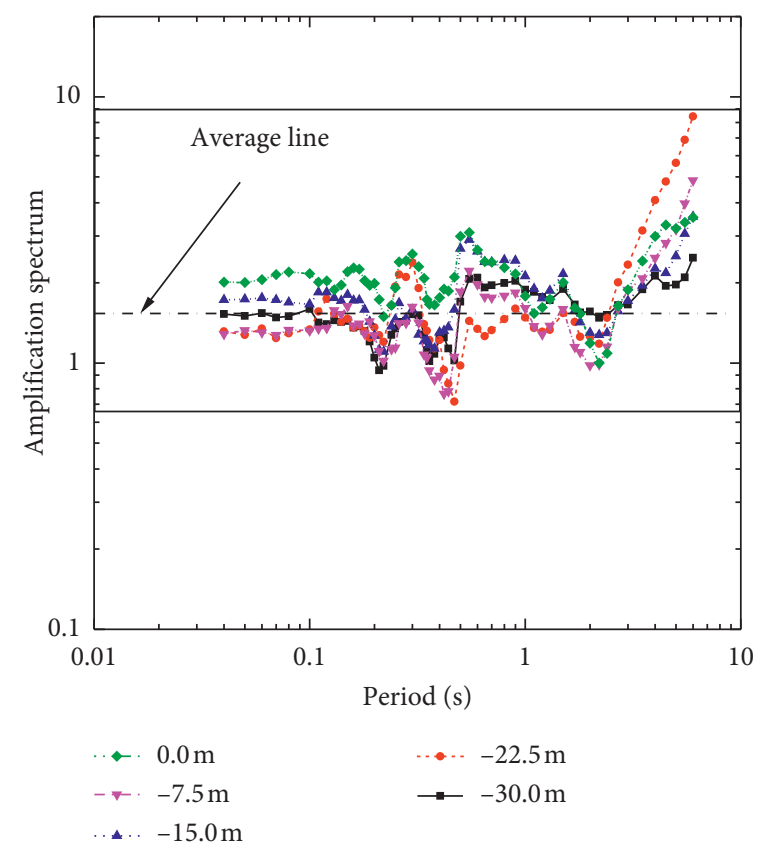

(b)

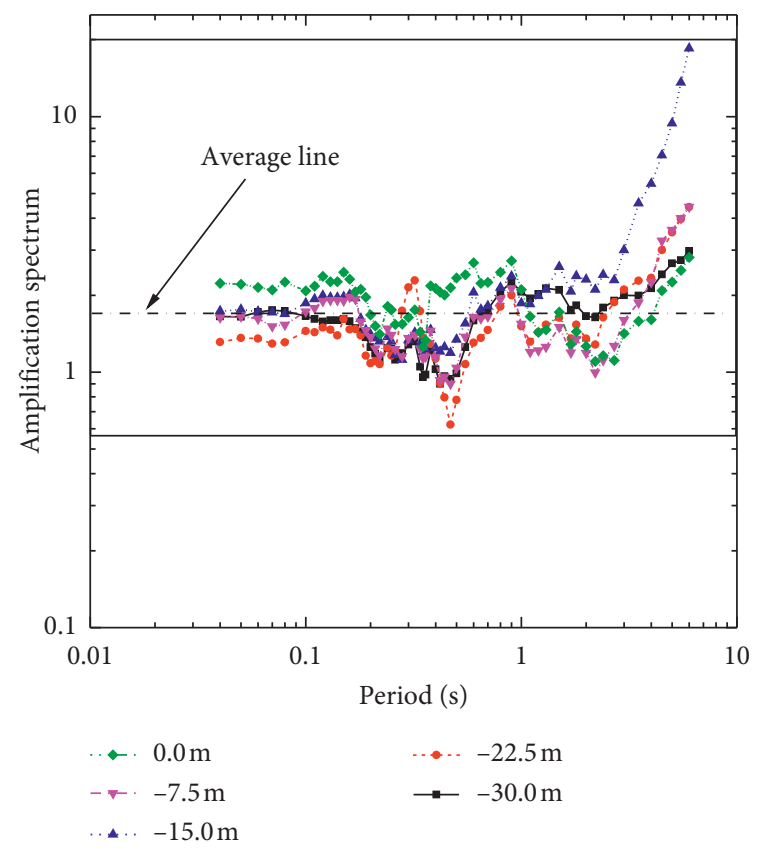

(d)

FIgURE 9: Normalized acceleration response spectrum. (a) EL-1; (b) EL-2; (c) EL-3; (d) EL-4.

indicated by the average line in the figure; the average is herein calculated as the mean value of all data at the five locations. Although the variation of the acceleration response spectrum ratio across the depth does not offer an evident trend, there are two notable observations about the apparent peak and lowest ratios shown in Figure 9. The lowest ratio occurs in the response spectrum period of $0.4 \mathrm{~s}$ to $0.6 \mathrm{~s}$, which corresponds to the maximum acceleration response spectrum shown in Figure 8; meanwhile, the highest spectral ratio appears at $6.0 \mathrm{~s}$ of the spectrum period, which coincides with the period for the lowest acceleration response spectrum (Figure 8).

\section{Conclusion}

The response of a moderately stiff site in seismic events is of significant importance in the analysis and assessment of the geotechnical and structural performance in earthquake engineering, as a moderate stiffness reflects the condition of a broad range of actual geomaterials on earth. The present 
study investigates the amplification effect of the ground motion across the depth of a moderately stiff soil via a centrifuge model test. A $75 \mathrm{~g}$ centrifugal acceleration is used and a similarity factor of 75 adopted in the design of the model test to simulate the response of a $30 \mathrm{~m}$ deep soil field. The acceleration peak value, time history, and response spectrum are carefully analyzed based on the measurements from the installed acceleration sensors through the soil in a series of tests where El Centro waves of different intensities are used. The ground motions recorded at different depths of the soil field show a high consistency in the waveform, basically retaining the initial waveform of the input seismic wave. The results of the present study show that the amplification factor tends to increase gradually from the bottom to the surface. The maximum amplification coefficient of the ground motions is found to vary between 1.95 and 2.19 and located close to the ground surface. The spectrum analysis of the ground motion shows that the acceleration response spectrum from the bottom to the surface tends to move to the high-frequency direction, and the value of the response spectrum decreases with the increase of the depth. The acceleration response spectrum ratio is found to vary between 0.7 and 10 with an average ratio of approximately $1.8 \sim 1.9$ in the present study.

\section{Data Availability}

The data used to support the findings and results of this study are available from the corresponding author upon request.

\section{Conflicts of Interest}

The authors declare that they have no conflicts of interest.

\section{Acknowledgments}

Jing-Yan Lan would like to acknowledge the financial support provided by the National Natural Science Foundation of China (\#51408559), Guangxi Natural Science Foundation (\#2018GXNSFAA281183), and the Doctoral Initiation Fund of Guilin University of Technology (\#GUTQDJJ2016025). This centrifuge test was strongly supported by the State Key Laboratory of Geological Disaster Prevention and Geological Environment Protection of Chengdu University of Technology, China. Jing-Yan Lan also wishes to express sincere gratitude to Prof. Yu-Jing Hou of China Institute of Water Resources and Hydropower Research, Prof. Qiang Xu, Prof. Wen-Xi Han, and Dr. Guang Zheng of Chengdu University of Technology, for their assistance during the centrifuge testing. A visiting scholarship from the Guangxi Education Department's Outstanding Teachers Training Abroad Program is also gratefully acknowledged.

\section{References}

[1] M. Çelebi, "Topographical and geological amplification: case studies and engineering implications," Structural Safety, vol. 10, no. 1-3, pp. 199-217, 1991.
[2] R. D. Borcherdt, "Effect of local geology on ground motion near San Francisco Bay," Bulletin of the Seismological Society of America, vol. 60, no. 1, pp. 29-61, 1970.

[3] D. J. Andrews, "Objective determination of source parameters and similarity of earthquakes of different size," Geophysical Monographes, vol. 37, no. 6, pp. 259-267, 1986.

[4] L. F. Bonilla, J. H. Steidl, G. T. Lindley, A. G. Tumarkin, and R. J. Archuleta, "Site amplification in the San Fernando Valley, California: variability of site-effect estimation using the S-wave, coda, and H/V methods," Bulletin of the Seismological Society of America, vol. 87, no. 3, pp. 710-730, 1997.

[5] Y. Nakamura, "A Method for dynamic characteristics estimations of subsurface using microtremors on the ground surface," Quarterly Report of Railway Technical Research Institute of Japanese National Railways, vol. 30, no. 1, pp. 25-33, 1989.

[6] P. P. Martin and H. B. Seed, "One-dimensional dynamic ground response analysis," Journal of the Geotechnical Engineering Division, vol. 108, no. 7, pp. 935-952, 1982.

[7] I. M. Idriss and H. B. Seed, "Seismic response of horizontal soil layers," Journal of the Soil Mechanics and Foundation Division, vol. 95, no. 4, pp. 693-698, 1968.

[8] P. B. Schnabel, J. Lysmer, and H. B. Seed, "SHAKE: a computer program for earthquake response analysis of horizontal layer sites," Report No. EERC 72-12, University of California at Berkeley, Earthquake Engineering Research Center, Berkeley, CA, USA, 1972.

[9] V. L. Streeter, E. B. Wylie, and F. E. Richart, "Soil motion computation by characteristic method," Journal of the Geotechnical Engineering Division, GT3, vol. 100, , pp. 247-263, 1974.

[10] K. W. Lee and W. D. L. Finn, "DESRA-2: dynamic effective stress response analysis of soil deposits with energy transmitting boundary including assessment of liquefaction potential," Soil Mechanics Series, Vol. Vol. 38, University of British Columbia, Vancouver, Canada, 1978.

[11] Y. M. A. Hashash and D. Park, "Non-linear one-dimensional seismic ground motion propagation in the Mississippi embayment," Engineering Geology, vol. 62, no. 13, pp. 185-206, 2001.

[12] D. C. F. Presti, C. G. Lai, and I. Puci, "ONDA: computer code for nonlinear seismic response analysis of soil deposits," Journal of Geotechnical and Geoenvironmental Engineering, vol. 132, pp. 223-236, 2006.

[13] H. H. M. Hwang, H. Lin, and J.-R. Huo, "Site coefficients for design of buildings in eastern United States," Soil Dynamics and Earthquake Engineering, vol. 16, no. 1, pp. 29-40, 1997.

[14] International Conference of Building Officials (ICBO), Uniform Building Code, Vol. Volume 2, Structural Engineering Design Provisions, United States of America, Whittier, CA, 1997.

[15] Building Seismic Safety Council (BSSC), NEHRP Recommended Provisions for Seismic Regulations for New Buildings and Other Structures FEMA 450, Part 1 (Provisions) and Part 2 (Commentary), Federal Emergency Management Agency, Washington, DC, 2004.

[16] Ministry of Construction of the People's Republic of China (MCPRC), General Administration of Quality Supervision, Inspection and Quarantine of the People's Republic of China. Code for Seismic Design of Buildings, China Architecture \& Building Press, Beijing, (in Chinese), 2010.

[17] Y. Hu, GB18306-2001: Seismic Ground Motion Parameter Zonation Map of China, Standards Press of China, Beijing, China, (in Chinese), 2001. 
[18] R. Dobry, R. D. Borcherdt, C. B. Crouse et al., "New site coefficients and site classification system used in recent building seismic code provisions," Earthquake Spectra, vol. 16, no. 1, pp. 41-67, 2000.

[19] V. Y. Sokolov, C.-H. Loh, and K.-L. Wen, "Evaluation of generalized site response functions for typical soil classes (B, C, and D) in Taiwan," Earthquake Spectra, vol. 20, no. 4, pp. 1279-1316, 2004.

[20] G. D. Bouckovalas and A. G. Papadimitriou, "Numerical evaluation of slope topography effects on seismic ground motion," Soil Dynamics and Earthquake Engineering, vol. 25, no. 7-10, pp. 547-558, 2005.

[21] N. S. Carpenter, Z. Wang, E. W. Woolery, and M. Rong, "Estimating site response with recordings from deep boreholes and HVSR: examples from the Mississippi Embayment of the central United States," Bulletin of the Seismological Society of America, "Bulletin of Seismological Society of America, vol. 108, no. 3A, pp. 1199-1209, 2018.

[22] F. Sedaghati, S. Pezeshk, and N. Nazemi, "Site amplification within the Mississippi embayment of the central United States: investigation of possible differences among various phases of seismic waves and presence of basin waves," Soil Dynamics and Earthquake Engineering, vol. 113, pp. 534-544, 2018.

[23] T. Lai, A. Elgamal, Z. Yang, D. W. Wilson, and B. L. Kutter, "Numerical modeling of dynamic centrifuge experiments on a saturated dense sand stratum," Proceedings of 11th International Conference on Soil Dynamic \& Earthquake Engineering and 3rd International Conference on Earthquake Geotechnical Engineering, pp. 558-565, University of California, Berkeley, 2004.

[24] C.-J. Lee, Y.-C. Wei, and Y.-C. Kuo, "Boundary effects of a laminar container in centrifuge shaking table tests," Soil Dynamics and Earthquake Engineering, vol. 34, no. 1, pp. 37-51, 2012.

[25] J. Liu, D. Zhao, X. Zhang, and W. Wang, "Dynamic centrifuge model tests on an unconfined soil foundation," Chinese Journal of Geotechnical Engineering, vol. 35, no. 5, pp. 980987, 2013, (in Chinese).

[26] K. B. Afacan, Evaluation of Nonlinear Site Response of Soft Clay Using Centrifuge Models, Ph.D. thesis, University of California at Los Angeles, Los Angeles, CA, 2014.

[27] Y. M. A. Hashash, S. Dashti, M. I. Romero, M. Ghayoomi, and M. Musgrove, "Evaluation of 1-D seismic site response modeling of sand using centrifuge experiments," Soil Dynamics and Earthquake Engineering, vol. 78, pp. 19-31, 2015.

[28] H. Kawase and K. Aki, "A study on the response of a soft basin for incident $S, P$, and Rayleigh waves with special reference to the long duration observed in Mexico City," Bulletin of the Seismological Society of America, vol. 79, no. 5, pp. 1361-1382, 1989.

[29] B. A. Gomez and G. R. Saragoni, "Interpretation of dynamic soil effects on Mexico City valley using the dense accelerograph network," Proceedings of the 5th International Conference on Seismic Zonation, vol. Vol. 1pp. 747-754, Nice, France, 1995.

[30] B. O. Hardin and W. L. Black, "Vibration modulus of normally consolidated clay," Journal of the Soil Mechanics and Foundations Division, SM2, vol. 94, , pp. 353-369, 1968.

[31] J. Cao, L. Han, C. Feng, and M. Huang, "Dynamic centrifuge tests on free-field response of soft soil," Journal of Yangtze River Scientific Research Institute, vol. 29, no. 2, pp. 78-82, 2012, (in Chinese).
[32] B. Mohraz, "A study of earthquake response spectra for different geological conditions," Bulletin of the Seismological Society of America, vol. 66, no. 3, pp. 915-935, 1976. 